WSRC-TR-93-011

\title{
ACID SOLUTION ABSORPTION OF EXTRUDED POLYETHYLENE FOAM (U)
}

\author{
by E. A. Kyser
}

Westinghouse Savannah River Company

WSRC-TR--93-011

Savannah River Site

Aiken, South Carolina 29808

Other Authors:

This paper was prepared in connection with work done under Contract No. DE-AC09-89SA18035 with the U.S. Department of Energy. By acceptance of this paper, the publisher and/or recipient acknowledges the U.S. Government's right to retain a nonexclusive, royalty-free license in and to any copyright covering this paper, along with the right to reproduce and to authorize others to reproduce all or part of the copyrighted paper.

\section{MASTER}


WSRC-TR-93-011

$\mathrm{Pg} 1$ of 12

Acid Solution Absorption of Extruded Polyethylene Foam (U)

E. A. Kyser $\in$ A 3

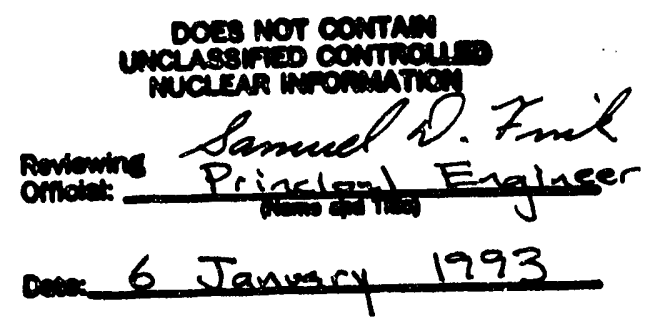

Westinghouse Savannah River Company

Savannah River Site

Aiken, SC 29808 


\section{DISCLAIMER}

This report was prepared by Westinghouse Savannah River Company (WSRC) for the United States Department of Energy under Contract No. DE-AC09-89SR19035 and is an account of work performed under that contract. Neither the United States Department of Energy, nor WSRC, nor any of their employees makes any warranty, expressed or implied, or assumes any legal liability or responsibility for the accuracy, completeness, or usefulness, of any information, apparatus, or product or process disclosed herein or represents that its use will not infringe privately owned rights. Reference herein to any specific commercial product, process, or service by trademark, name, manufacturer, or otherwise does not necessarily constitute or imply endorsemen:, recommendation, or favoring of same by WSRC or by the United States Government or any agency thereof. The views and opinions of the authors expressed herein do not necessarily state or reflect those of the United States Government or any agency thereof. 
Acid Solution Absorption of Extruded Polyethylene Foam (U)

E. A. Kyser

January 6, 1993

Westinghouse Savannah River Company

Savannah River Site

Aiken, SC 29808 
WSRC-TR-93-011

$\mathrm{Pg} 4$ of 12

TABLE OF CONTENTS

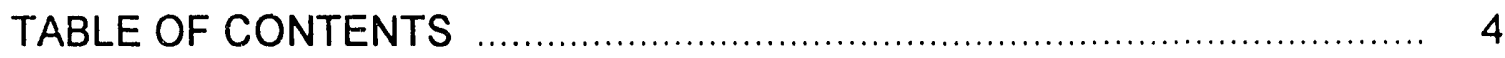

SUMMARY

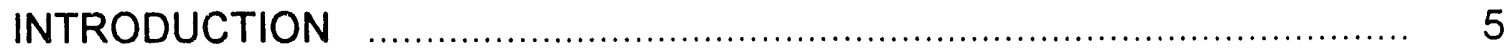

TEST MATERIAL

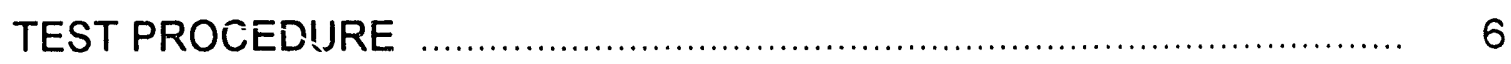

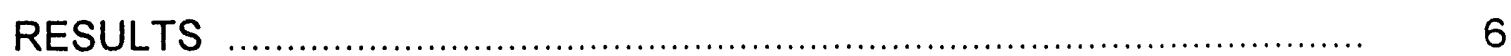

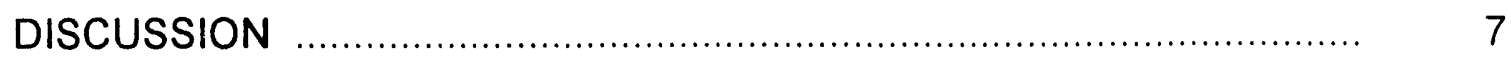

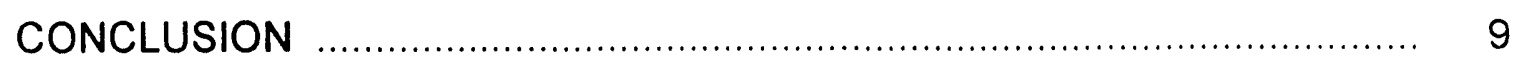

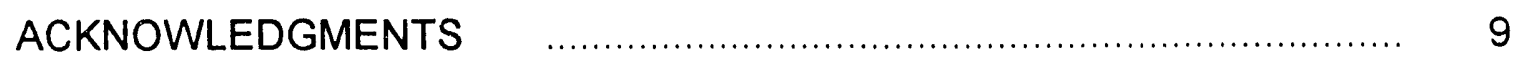

REFERENCES

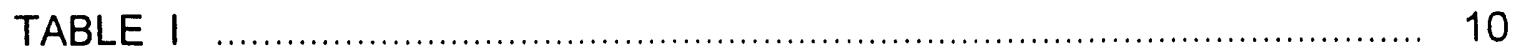

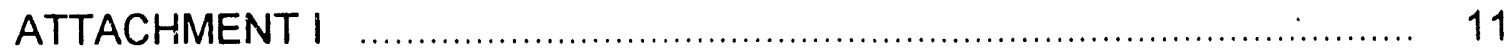

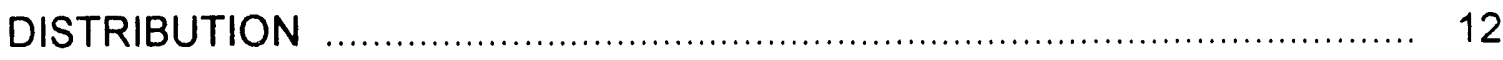


WSRC-TR-93-011

$\mathrm{Pg} 5$ of 12

\title{
Acid Solution Absorption of Extruded Polyethylene Foam (U)
}

\author{
by E. A. Kyser \\ Westinghouse Savannah River Company \\ Savannah River Site \\ Aiken, SC 29808
}

\section{SUMMARY:}

Water and acid absorption tests of samples of a proposed replacement to current polyethylene foam used as fill material on the FB-Line cation columns have been completed. Water and nitric acid solution absorption of up to 4 volume percent was observed over approximately a 4 month period of time. Because of the nuclear safety implications, liquid absorption of a replacement fill material must be low. Ethafoam ${ }^{\mathrm{TM}}$ 220 extruded polyethylene, a product available from Dow Chemical Company appears to be a good candidate material for replacement of the existing fill material. Establishment of 5 volume percent solution absorption specification appears to be both reasonable and achievable for a replacement foam, provided it is acceptable to nuclear safety personnel.

\section{INTRODUCTION:}

The cation exchange columns in FB-Line consist of 10 inch diameter segments which are filled with Dowex ${ }^{\circledR 5} 5$ strong acid cation resin. The bed of resin is approximately 5 inches in depth and $\mathrm{Pu}^{+3}$ is loaded from $2 \mathrm{BP}$ sent from $\mathrm{F}$ canyon. This process serves to concentrate the dilute $\mathrm{Pu}$ stream from $\mathrm{F}$-Canyon prior to precipitation in FB-Line. The equipment design allows for shrinkage and swelling of the resin during piucess cycles with a spring loaded upper plate. In designing the column to accommodate the spring movement, a well is created on top of the column which could fill with solution in the event of leakage of solution around the seal of the upper plate or flange. Per the original design, this void space was filled with extruded polyethylene to prevent accumulation of Pu bearing solution. Polyethylene in this form is mostly air that is sealed in pockets within the material and provides low neutron reflection/moderation potential when evaluated for nuclear safety. This foam filler does not form a seal with the equipment and all liquid flows through the equipment are performed with gravity pressure head.

The concern of this study is how much solution will the foam absorb under atmospheric pressure. Documentation on the physical characteristics that led to the selection of the original foam is not available. No liquid absorption by the foam is not a realistic expectation; however, the amount of liquid absorption that is acceptable from a nuclear safety standpoint is not known. Some analysis will be required to provide a basis for acceptance of a replacement foam. 
WSRC-TR-93-011

$\mathrm{Pg} 6$ of 12

The foam that is currently in place has been in use for many years and its suitability for future use is questionable. Some testing of the existing foam has been attempted in FB-Line but the results do not appear encouraging. A replacement foam is being sought and Ethafoam ${ }^{\mathrm{TM}} 220$ is one being considered as a replacement for the existing material. This foam is manufactured as a packing material for shipment of electronics and other products. The manufacturer does not state the amount of liquid that this material would be expected to absorb, therefore it was necessary to test samples for this property. Process leaks could involve exposure of the foam to nitric acid/sulfamic solutions of Pu ranging from 0.1 to 5 molar $\mathrm{HNO}_{3}$. This report documents tests that were performed with samples of Ethafoam ${ }^{\mathrm{TM}} 220$ submerged in water and 5 molar $\mathrm{HNO}_{3}$ over a period of 4 months.

\section{TEST MATERIAL:}

Polyethylene has a density of $0.91-0.965 \mathrm{~g} / \mathrm{cc}$ depending on whether it is low or high density polymer. Dow literature states that Ethafoam ${ }^{\mathrm{TM}} 220$ has an density of 0.035 $\mathrm{g} / \mathrm{cc}$ (samples measured $0.041-0.043 \mathrm{~g} / \mathrm{cc}$ ). Ethafoam ${ }^{\mathrm{TM}} 220$ therefore appears to be approximately 4.6 percent polyethylene and 95.4 percent air as calculated from the density. Test samples of Ethafoam ${ }^{\mathrm{TM}} 220$ were obtained from United Foam Plastics Corporation in April 1992 by FB-Line Technical. A portion of this sample was cut in half to form two similar blocks of foam approximately $15 \mathrm{~cm}$ by $10=\mathrm{m}$ by $3 \mathrm{~cm}$.

\section{TEST PROCEDURE:}

The objective was to determine the quantity of process solution this foam would absorb. Tests were performed by submerging foam blocks in solutions contained in shallow stainless steel pans. Two samples were tested; one in deionized water and the other in 5 molar $\mathrm{HNO}_{3}$. The samples were kept submerged by applying sufficient weight on top of the samples. The weight of each sample of foam was measured on a calibrated analytical balance with a precision of $0.1 \mathrm{mg}$. The dry samples weighed 15-17 grams each. The bottom and side faces of the blocks were kept submerged and the manufacturer's facing (a somewhat smoothed uncut surface) was kept on top. The samples were weighed periodically during the test according to a procedure. This weighing procedure required the excess solution to be removed from the foam sample by blotting with an absorbent wipe to remove the fluid clinging to the sample surface. Two mass measurements were made: one immediately after blotting and another after 5 minutes to allow for surface evaporation. Measurements taken immediately after blotting exhibited significant variability due to rapid continued evaporation of surface liquid. After 5 minutes, a mass measurement was considerably more stable. Both values are reported because they give an indication of the uncertainty in the ability to measure absorption by this technique; however, the true value is assumed to be the 5 minute value. Periodically during the test the balance was checked with a calibration mass to ensure it was functioning properly.

\section{RESULTS:}

Both samples showed that they were capable of doubling their weight by the 
absorption of water or 5 molar nitric acid solution. Because the volume of the foam occupied by liquid is important (rather than the weight gain), weight gains were converted to values of volume percent taking into account the density of the solution and the size of each foam sample. Both samples gained liquid on the order of 3 to 4 percent during the course of the test. Figure 1 is a graph of the variation in volume percent liquid absorption over the course of roughly 4 months of testing (the full data results are included in Table 1 at the end of this report). Although there are considerable transient variations in the results, it appears that it would be difficult to attain greater than 5 volume percent absorption of liquid. The size of the blocks of foam were carefully measured prior to the work and periodically during the testing as well as at the end. No swelling or shrinkage of the test samples was observed. No evidence of change in the physical appearance of the foam samples was observed that would imply chemical attack by acid or water.

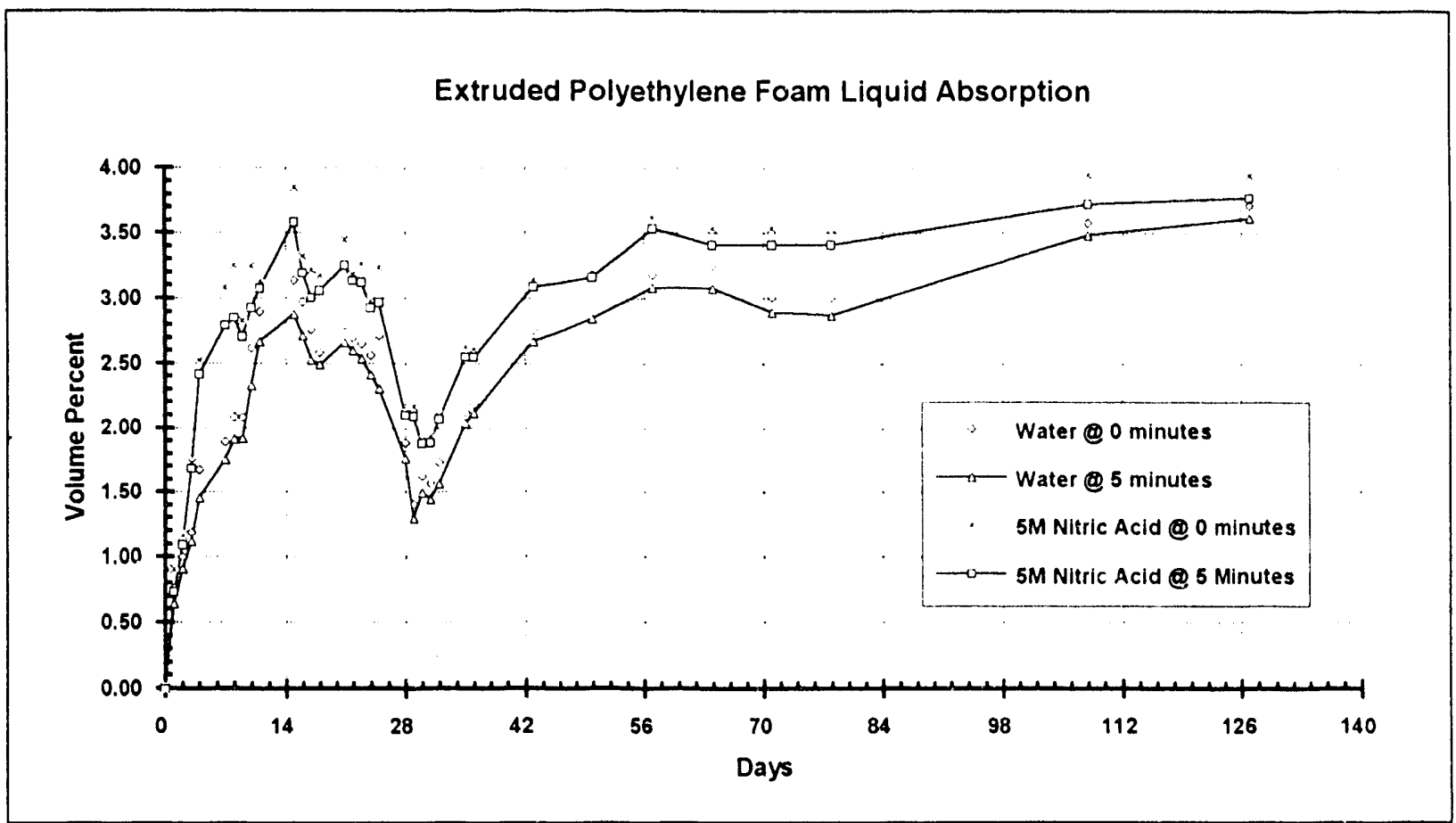

Figure 1. Liquid Absorption by Ethafoam ${ }^{\mathrm{TM}} 220$ as a Function of Time

Three observations were noted during the period of testing: (1) the acid sample appeared to absorb more volume of liquid than the water sample, (2) the time between measurements seemed to affect the rate of absorption, and (3) the technique of blotting the foam is highly sensitive to the person performing the task.

\section{DISCUSSION:}

Variation between Acid and Water Absorption: Throughout the test, the results suggest that more acid was being absorbed than water. Near the end of the test, when measurements were taken monthly, these differences were small. These observations are likely due more to the nature of the test conditions rather than actual differences in 
absorption of different solutions. Amu ant temperature, evaporation rates, and acid strength all varied during the test and contributed to an unknown degree to the variations that were observed. These samples sat on the bench top over a period of time that the laboratory's ambient temperature was changing. Additionally, measurements of the solution temperature showed that the water pan was generally several degrees centigrade cooler than that of the 5 molar nitric acid pan. This was caused by the different evaporative cooling effects on the two shallow pans of solution. To what degree, if any, this affected the results is unclear. Also during the course of the experiment, solution volume loss due to evaporation had to be compensated for. Early in the experiment, additional 5 molar acid was added to keep the volume constant. Since more water than nitric acid was evaporating, the acid concentration increased to approximately 7 molar. When this was noted, the acid solution was replaced and future additions were made with water only. However, at the end of the experiment, the acid concentration had dropped to riearly 3 molar. This unanticipated complication appeared to have little if any effect on the overall results.

Time between Measurements: Initially measurements were taken each work day, later this was extended to once each week and eventually monthly. When daily measurements were in progress the trend was for the values to decline slightly over the course of the week and to increase over the weekend. Both samples showed changes in the same direction at almost every meas ' rement point. When a measurement frequency of weekly or monthly was used, gradual increases in the moisture absorption were noted. It appeared that the measurement process itself affected the absorption values when daily measurements were made. However, the final values at the end of 127 days are not greatly different than those seen at the 14 to 20 day region. Therefore, the peak value from a 2 to 3 week test appears to represent a reasonable maximum in the absorption. The rate of change observed near the end of this test established with confidence that a limiting liquid absorption was being reached and that significantly higher values would not occur even when exposed over a longer time frame.

Blotting Technique: The significant loss of absorbed liquid seen during the fourth week of testing coincided with use of a different technician performing the measurements. This technician apparently used a firmer technique to blot the foam and may have pressed liquid out of the samples. After that week and the return of the original technician, the frequency of measurement was reduced from daily to weekly and the values rose back to the earlier observed range after one week's exposure.

Pressure Head: The effect of pressure on liquid absorption of foam was not studied in this experiment because it is not applicable to the actual operation of the equipment. Gravity head is used to flow solution through this equipment (so the pressures involved are never large) and the foam as used does not seal the top of the equipment. Leakage around the top plate would fill the tiny space between the foam and the housing until it overflowed the top of the equipment where it would become visible. The purpose of this work was limited to establishing that minor, undetectable seepage would not be absorbed by the filler material in significant amounts and remain undetected over time. 


\section{CONCLUSION:}

Samples of Ethafoam ${ }^{\mathrm{TM}} 220$ showed minimal liquid absorption from either water or 5 molar nitric solutions during submersion testing during a period of 127 days. The maximum absorption value never exceeded 4 volume percent and it appears that exceeding 5 volume percent liquid absorption would not be possible under the ambient pressure conditions existing in the process. Establishment of a limit of 5 volume percent liquid absorption as a maximum allowed for replacement materials appears to be both reasonable and achievable using Ethafoam ${ }^{\mathrm{TM}} 220$, assuming that this value is acceptable from a nuclear safety evaluation. Because of the implication to nuclear safety and the lack of a manufacturer's specification, a three week absorption test with a sample from the actual foam shipped is recommended to determine acceptance of replacement extruded polyethylene foam.

\section{ACKNOWLEDGMENTS}

This work benefitted from the constructive comments of S.D. Fink and J.B. Schaade and the dedicated efforts of K.J. Kalbaugh in performing the testing.

\section{REFERENCES}

1Dow literature, Ethafoam ${ }^{\mathrm{TM}}$ Brand Plastic Foam, Form No. 172-1133-290

2 United Foam Plastics Corporation, Fairburn GA, (404-964-5888), Order Form $3134,4 / 28 / 92$

3Laboratory Notebook E48305, E.A. Kyser, DPSTN-4579, October 22, 1987 
WSRC-TR-93-011

$\mathrm{Pg} 10$ of 12

\begin{tabular}{|c|c|c|c|c|c|c|c|c|c|c|c|}
\hline & \multirow{3}{*}{ Day } & \multicolumn{5}{|c|}{ Sample A: DI Water Absorption } & \multicolumn{5}{|c|}{ Sample B: 5M Nitric Acid Absorption } \\
\hline & & \multicolumn{2}{|c|}{ Raw Data } & \multicolumn{2}{|c|}{5 Min Values } & \multirow{2}{*}{$\begin{array}{l}\text { Initial } \\
\text { Vol \% } \\
\text { Liquid }\end{array}$} & \multicolumn{2}{|c|}{ Raw Dala } & \multicolumn{2}{|c|}{5 Min Values } & \multirow{2}{*}{$\begin{array}{l}\text { Initial } \\
\text { Vol \% } \\
\text { Liquid }\end{array}$} \\
\hline & & $\begin{array}{c}\text { Initial } \\
\text { Weight } \\
\end{array}$ & $\begin{array}{c}5 \mathrm{~min} \\
\text { Weight } \\
\end{array}$ & $\begin{array}{c}\text { Weight } \\
\text { Gain }\end{array}$ & $\begin{array}{l}\text { Vol \% } \\
\text { Liquid }\end{array}$ & & $\begin{array}{c}\text { Initial } \\
\text { Weight }\end{array}$ & $\begin{array}{c}5 \mathrm{~min} \\
\text { Weight }\end{array}$ & $\begin{array}{c}\text { Weight } \\
\text { Gain }\end{array}$ & $\begin{array}{l}\text { Vol \% } \\
\text { Liquid }\end{array}$ & \\
\hline 08-May-92 & Initial Wgt & 14.8933 & 14.8931 & 14.8932 & & & 17.2499 & 17.2500 & 17.2500 & & \\
\hline 08-May-92 & Initial Volume & 363.97 & & & & & 405.32 & & & & \\
\hline 08-May-92 & Wetted Wgt & 15.2780 & 15.0725 & 0.1793 & 0.05 & 0.11 & 17.7290 & 17.5277 & 0.2778 & 0.06 & 0.10 \\
\hline $11-$ May-92 & Dry Wgt & & 14.8382 & -0.0550 & -0.02 & & & 17.1893 & -0.0606 & .0 .01 & \\
\hline 12-May-92 & Day 1 & 17.6435 & 17.2305 & 2.3373 & 0.64 & 0.76 & 21.4978 & 20.6642 & 3.4143 & 0.73 & 0.90 \\
\hline 13-May-92 & Day 2 & 18.5218 & 18.1920 & 3.2988 & 0.91 & 1.00 & 22.7042 & 22.3612 & 5.1113 & 1.09 & 1.16 \\
\hline 14-May-92 & Day 3 & 19.2044 & $18.977 ?$ & 4.0845 & 1.12 & 1.18 & 25.3702 & 25.1593 & 7.9094 & 1.68 & 1.73 \\
\hline 15-May-92 & Day 4 & 20.9780 & 20.1852 & 5,2920 & 1.45 & 1.67 & 29.1121 & 28.5898 & 11.3399 & 2.41 & 2.52 \\
\hline 18-May-92 & Day 7 & 21.7736 & 21.2735 & 6.3803 & 1.75 & 1.89 & 31.7393 & 30.3715 & 13.1216 & 2.79 & 3.08 \\
\hline 19-May-92 & Day 8 & 22.4851 & 21.8543 & 6.9611 & 1.91 & 2.09 & 32.5362 & 30.6395 & 13.3896 & 2.85 & 3.25 \\
\hline 20-May-92 & Day 9 & 22.4655 & 21.8874 & 6.9942 & 1.92 & 2.08 & 30.5472 & 29.9687 & 12.7188 & 2.71 & 2.83 \\
\hline 21-May-92 & Day 10 & 24.4209 & 23.3560 & 8.4628 & 2.33 & 2.62 & 32.5033 & 31.0052 & 13.7553 & 2.93 & 3.24 \\
\hline 22-May-92 & Day 11 & 25.4324 & 24.6029 & 9.7097 & 2.67 & 2.90 & 31.9716 & 31.6947 & 14.4448 & 3.07 & 3.13 \\
\hline 26-May-92 & Day 15 & 26.3109 & 25.3795 & 10.4863 & 2.88 & 3.14 & 35.3581 & 34.0885 & 16.8386 & 3.58 & 3.85 \\
\hline 27-May-92 & Day 16 & 25.7164 & 24.7781 & 9.8849 & 2.72 & 2.97 & 32.8671 & 32.2548 & 15.0049 & 3.19 & 3.32 \\
\hline 28-May-92 & Day 17 & 24.9502 & 24.0905 & 9.1973 & 2.53 & 2.76 & 32.3742 & 31.3758 & 14.1259 & 3.00 & 3.22 \\
\hline 29-May-92 & Day 18 & 24.2925 & 23.9520 & 9.0588 & 2.49 & 2.58 & 32.1558 & 31.6200 & 14.3701 & 3.06 & 3.17 \\
\hline $01-J u n-92$ & Day 21 & 25.0705 & 24.5925 & 9.6993 & 2.66 & 2.80 & 33.4763 & 32.5190 & 15.2691 & 3.25 & 3.45 \\
\hline 02-Jun-92 & Day 22 & 24.7140 & 24.3541 & 9.4609 & 2.60 & 2.70 & 32.2218 & 31.9849 & 14.7350 & 3.13 & 3.18 \\
\hline 03-Jun-92 & Day 23 & 24.5572 & 24.1325 & 9.2393 & 2.54 & 2.66 & 32.5947 & 31.9222 & 14.6723 & 3.12 & 3.26 \\
\hline 04-Jun-92 & Day 24 & 24.2201 & 23.6701 & 8.7769 & 2.41 & 2.56 & 31.2422 & 31.0121 & 13.7622 & 2.93 & 2.98 \\
\hline 05-Jun-92 & Day 25 & 24.7677 & 23.2675 & 8.3743 & 2.30 & 2.71 & 32.4584 & 31.2010 & 13.9511 & 2.97 & 3.23 \\
\hline 08-Juni-92 & Day 28 & $21.7+29$ & 21.3038 & 6.4106 & 1.76 & 1.88 & 27.1973 & 27.1043 & 9.8544 & 2.10 & 2.12 \\
\hline 09-Jun-92 & Day 29 & 20.0090 & 19.6120 & 4.7188 & 1.30 & 1.41 & 27.4413 & 27.0670 & 9.8171 & 2.09 & 2.17 \\
\hline 10-Jun-92 & Day 30 & 20.8030 & 20.3420 & 5.4488 & 1.50 & 1.62 & 26.2221 & 26.0731 & 8.8232 & 1.88 & 1.91 \\
\hline 11-Jun-92 & Day 31 & 20.6085 & 20.1640 & 5.2708 & 1.45 & 1.57 & 26.3335 & 26.0981 & 8.8482 & 1.88 & 1.93 \\
\hline 12-Jun-92 & Day 32 & 21.1875 & 20.5864 & 5.6932 & 1.56 & 1.73 & 27.1180 & 26.9523 & 9.7024 & 2.06 & 2.10 \\
\hline 15-Jun-92 & Day 35 & 22.6216 & 22.3070 & $7 .+138$ & 2.04 & 2.12 & 29.6128 & 29.2262 & 11.9763 & 2.55 & 2.63 \\
\hline 16-Jun-92 & Day 36 & 22.8417 & 22.5975 & 7.7043 & 2.12 & 2.18 & 29.5205 & 29.2222 & 11.9723 & 2.55 & 2.61 \\
\hline 23-Jun-92 & Day 43 & 24.9265 & 24.6121 & 9.7189 & 2.67 & 2.76 & 32.0025 & 31.7668 & 14.5169 & 3.09 & 3.14 \\
\hline 30-Jun-92 & Day 50 & 25.6473 & 25.2510 & 10.3578 & 2.85 & 2.95 & 32.3030 & 32.0940 & 14.8441 & 3.16 & 3.20 \\
\hline 07-Jul-92 & Day 57 & 26.4882 & 26.1175 & 11.2243 & 3.08 & 3.19 & 34.2850 & 33.8698 & 16.6199 & 3.53 & 3.62 \\
\hline 14-Jul-92 & Day 64 & 26.7505 & 26.1104 & 11.2172 & 3.08 & 3.26 & 33.8885 & $\$ 3.2710$ & 16.0211 & 3.41 & 3.54 \\
\hline $21-J u l-92$ & Day 71 & 25.8442 & 25.4480 & 10.5548 & 2.90 & 3.01 & 33.8885 & 33.2710 & 16.0211 & 3.41 & 3.54 \\
\hline 28-Jul-92 & Day 78 & 25.8531 & 25.3590 & 10.4658 & 2.88 & 3.01 & 33.8885 & 33.2710 & 16.0211 & 3.41 & 3.54 \\
\hline 27-Aug-92 & Day 108 & 27.9284 & 27.5704 & 12.6772 & 3.48 & 3.58 & 35.8280 & 34.7595 & 17.5096 & 3.72 & 3.95 \\
\hline 15-Sep-92 & Day 127 & 28.4180 & 28.0544 & 13.1612 & 3.62 & 3.72 & 35.8172 & 34.9860 & 17.7361 & 3.77 & 3.95 \\
\hline
\end{tabular}


WSRC-TR-93-011

$\mathrm{Pg} 11$ of 12

\section{Attachment 1:}

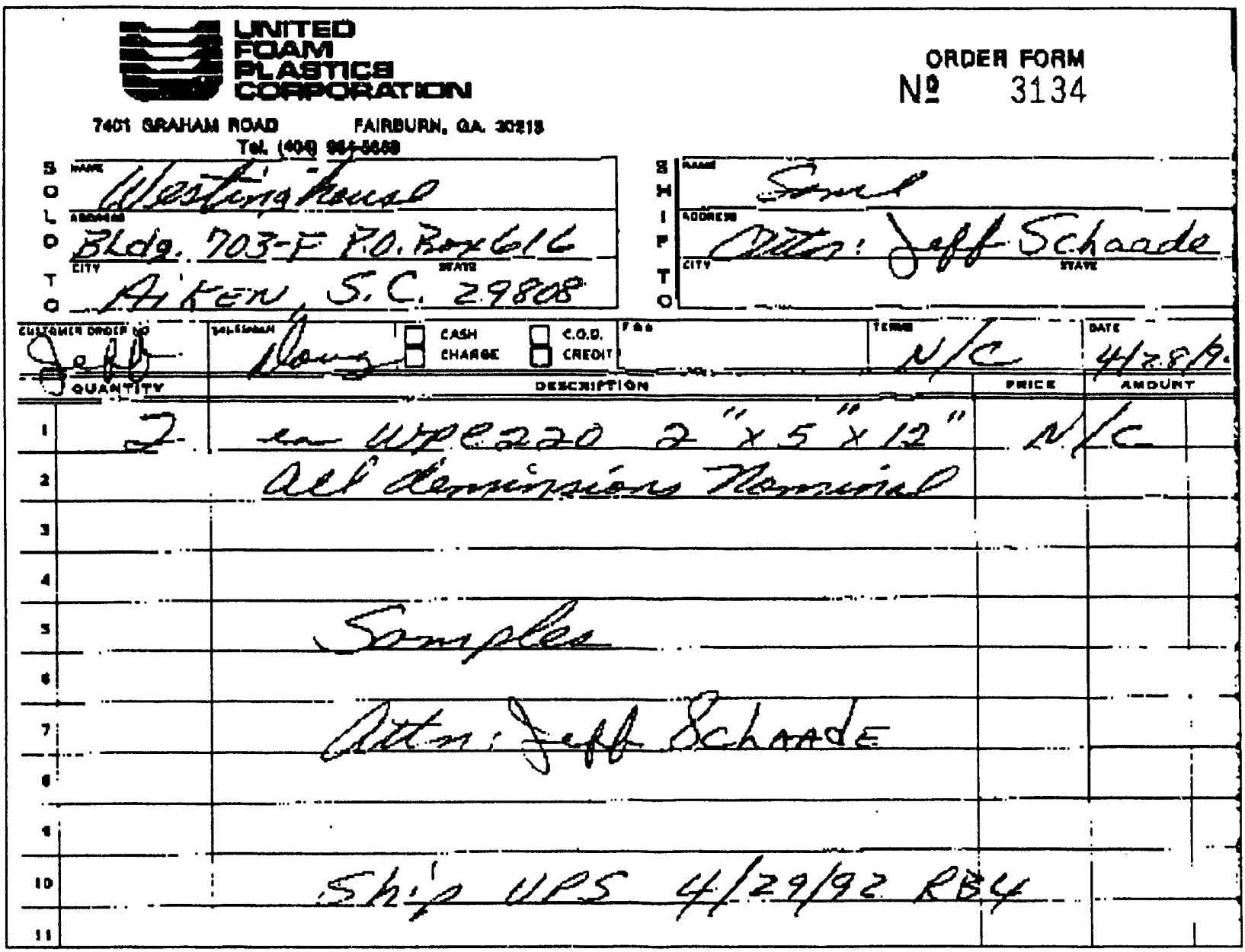


WSRC-TR-93-011

$\mathrm{Pg} 12$ of 12

DISTRIBUTION:

A. L. Blancett, 773-A

F. R. Graham, 773-A

S. D. Fink, 773-A

J. B. Schaade, 703-F

J. M. Brenneke, 703-F

T. A. Reilly, 707-F

L.A. Hedlund, 704-15F

J.W. McClard, 703-F

D.W. Murdoch, 703-F

SRTC Records(4) 
DATE

FILMED

5125193 
